\title{
TRABAJO SOCIAL Y ESTALLIDOS SOCIALES: REFLEXIONES Y ACCIONES*
}

\section{SOCIAL WORK AND SOCIAL OUTBREAK: REFLEXIONS AND ACTIONS}

\author{
Carlos Mejías Sandia \& Pablo Suárez Manrique ${ }^{1}$ \\ cmejiass@yahoo.com - psuarez@utem.cl \\ Universidad Autónoma de Chile - Universidad Tecnológica Metropolitana \\ Santiago, Chile \\ DOI: https://doi.org/10.32735/S2735-61752020000117148
}

\section{RESUMEN}

La historia disciplinaria ha transitado desde lo benéfico asistencial o caritativo, hasta lo tecnocrático y desarrollista orientado hacia el ajuste y la adaptación. Actualmente atravesamos un nuevo momento, quizás el más complejo. El estallido social o revuelta popular ofrecen una oportunidad profesional y disciplinaria para colaborar en revertir la tradicional hegemonía de un modelo de respuesta focalizada y atomizada en la dimensión individual-familiar del "beneficio" y la "asistencia". De esta manera este artículo busca establecer las coerciones actuales de esta disciplina y cómo ello influye en su accionar para levantar, repensar y relegitimar el actuar de los Trabajos Sociales Otros o críticos en estos u otros escenarios de crisis del modelo capitalista neoliberal en perspectiva de co-construir significados de las dignidades y dignificaciones en perspectivas descoloniales.

Palabras claves: estallido social; trabajos sociales otros; praxis; co-construcción; descolonialidad.

\begin{abstract}
Disciplinary history has ranged from the charitable or charitable, to the technocratic and developmental oriented towards adjustment and adaptation. We are currently going through a new moment, perhaps the most complex. The social outbreak or popular revolt offers a professional and disciplinary opportunity to collaborate in reversing the traditional hegemony of a model of focused and atomized response in the individual-family dimension of "benefit" and "assistance". In this way, this article seeks to establish the current constraints of this discipline and how this influences its actions to lift, rethink and re-legitimize the actions of Other Social Work or critics in these or other crisis scenarios of the neoliberal capitalist model in perspective of co -construct meanings of dignities and dignifications in decolonial perspectives.
\end{abstract}

Key words: social outbreak; other social work; praxis; co-construction; decoloniality.

\footnotetext{
* Artículo recibido el 3 de junio de 2019; aceptado el 28 de junio de 2019.

1 Carlos Mejías es Profesor de Castellano, Dr. en Sociología. Pablo Suárez es Máster en Políticas Sociales.
} 


\section{Introducción}

"El mundo está cambiando y cambiará más", así lo cantaban el grupo musical uruguayo los Iracundos en la mitad de los sesenta, unos años más tarde Mercedes Sosa interpretaba la canción compuesta por Julio Numhauser que en su letra señala: "Cambia lo superficial, cambia también lo profundo, cambia el modo de pensar, cambia todo en este mundo".

Los cambios y los movimientos sociales parecen ir de la mano en la historia de Latinoamérica desde la llegada del "conquistador". Las primeras manifestaciones fueron de los y las nativos/as que resistieron al dominio cultural de sus civilizaciones, ya sea de manera oculta o acompañada de reacciones violentas y significativas para cada época y territorio. Otro tanto, sucedió al momento de la llamada independencia que rechazó el dominio colonial, pero mantuvo y profundizó la "colonialidad". Durante el periodo de las Repúblicas, los cambios fueron impulsados por movimientos revolucionarios, obreros, pobladores, mujeres etc. Pero también hubo cambios reaccionarios de las oligarquías y sus fuerzas militares que originaron muerte y desolación.

En Latinoamérica, en las últimas décadas e igual que el pasado, se siguen presentando "alzamientos populares" que continúan demandando "cambios" pero que ahora se experimentan a nivel global con fuerza inusitada y bajo consignas similares y transversales. La saturación del modelo económico, sobreexplotación, crisis del neoliberalismo y un sinfín de etcéteras acompañan estas movilizaciones a nivel mundial. Lo concreto es que diversos y múltiples movimientos sociales, (indígenas, disidencias y diversidades sexuales, trabajadores de distintos sectores de la economía, medioambientalistas, feministas, animalistas por nombrar algunos) en su conjunto, han intentado volver a ser escuchados en sus demandas, en sus justicias, en sus humanidades, y ello, no ha estado exento de violencias.

Chile no estuvo ajeno a este resurgir planetario de la lucha social y en 2019 se produjo un levantamiento popular que puso en jaque a la institucionalidad política, judicial y policial, donde una de las consignas fue "aquí nació y aquí murió el neoliberalismo" (Fábrega, 2019; Monckeberg, 2019; Cortés, 2020). Los cientistas sociales acuñaron extrañamente, para este levantamiento, el nombre de "estallido social" como caracterización del fenómeno político, económico y cultural que irrumpe horizontalmente en la sociedad chilena, y que convocó a todo el país, de norte a sur, movilizando a millones de ciudadanos/as en protesta contra las desigualdades sociales, reclamando cambios profundos, equidad y justicia social.

Una interpretación más generalista de estos fenómenos lo atribuyen a una inesperada explosión de emociones y sentimientos acumulados durante más de 30 años ${ }^{2}$, donde la rabia, impotencia, indignación, injusticia, desconfianza, amargura son factores relevantes (Baeza 2019; Stange y otros 2019; Mac Clure et al. 2020) y que se conjuntan transversal y "espontáneamente" entre personas de diversos grupos y clases sociales que dan origen: "a la más profunda reacción ciudadana que se recuerde desde el fin de la dictadura militar en respuesta a las condiciones de

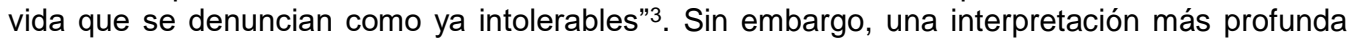
debiese considerar en sus análisis los procesos históricos e ideológico-políticos ocurridos en las últimas tres décadas en la sociedad chilena, incorporando elementos que permiten observar su

\footnotetext{
${ }^{2}$ Es el periodo de duración de los gobiernos democráticos después de 17 años de dictadura cívico y militar. Esos gobiernos prometieron acabar con las desigualdades y las injusticias. Aquello no sucedió, muy por el contrario, se agudizaron la corrupción, las desigualdades, la pérdida de derechos laborales, la precarización de la salud, vivienda, pensiones, de la educación.

${ }^{3}$ Estallido social en el Chile neoliberal. En: www.ongeco.cl.
} 
complejidad y extensión y que superan las interpretaciones nomotéticas e ideográficas de esta crisis social que todavía no se cierra.

El "levantamiento popular" de octubre y conceptualizado como "estallido social" materializó y consolidó una larga lucha de vastos colectivos, comunidades y organizaciones del pueblo y sectores medios, principalmente, que comenzaron a deslegitimar e instalar un discurso y una práctica de la inutilidad de las instituciones del Estado, especialmente las políticas públicas. Esto ha dado como resultado nuevas formas organizativas y otras maneras de ejercer la democracia, es decir, donde no predominan las clásicas prácticas institucionalizadas, sino las causas de diversa procedencia, lo que se conoce como activismo sincrónico y acción conectiva generacional (Reguillo, 2017). Estas acciones y discursos comienzan a instalarse con relativa fuerza en el campo de la política, transformándose en actores sociales colectivos que se enfrentan y reaccionan contra una realidad social opresiva y represiva del sistema de poder y hegemonía establecido.

Tras el coyunturalismo inicial y una aparente falta de conducción y orientación de las múltiples "manifestaciones", se comenzó a encubar un proceso que viene germinándose desde un pasado cercano 4 , y que se vio materializado en un movimiento social amplio, que reunió las constantes luchas por la educación, salud, reconocimiento de derechos, medioambiente, pensiones y muchas otras que se dieron y que siguen dándose. Las expresiones de luchas se han diversificado y continúan por un proceso ascendente y acumulativo en los territorios donde la conducción va labrándose desde la base social de los diversos colectivos, agrupaciones y "movimientos específicos" que se han ido articulando entre sí a medida que el proceso se ha complejizado y crecido.

Lo anterior implica, a lo menos, dos situaciones significativas, por una parte, la conjunción del aparentemente fragmentado discurso de las diversidades que resisten y se movilizan, generando una síntesis en la crítica global al sistema, sobre el consenso de su inviabilidad producto de los altísimos costos sociales que han generado en términos de desigualdades, exclusiones, violencias e injusticias. Por otra parte, denota, instala y legitima fuertemente la idea del agotamiento del modelo neoliberal.

Dado este escenario de cuestionamiento a la institucionalidad y al sistema de poder y hegemonía establecido. la clase dominante y el aparato represivo en su conjunto cierran filas en su defensa, ello implica la profundización de la violencia política que desborda con un velo de la impunidad e impudicia 5 . La mayoría de las personas afectadas fueron niños, jóvenes y adolescentes, todo ello respaldado por casi la totalidad de los partidos políticos institucionales

\footnotetext{
${ }^{4}$ Nos referimos a señales que comenzaron en los años noventa con los estudiantes universitarios y su lucha por el financiamiento de la educación superior, posteriormente en el 2006 son los estudiantes secundarios, en la llamada "revolución pingüina", que luchan por una educación digna y de calidad, la lucha de los universitarios el 2011 por gratuidad, las luchas del pueblo mapuche por sus tierras y derechos ancestrales, de los trabajadores contra las AFP por pensiones más dignas, de las mujeres por la igualdad de género y sus derechos sexuales y reproductivos, de la diversidad sexual por su reconocimiento, los medioambientalistas contra las represas y un sinfín de luchas que no alcanzaron una dimensión nacional pero que localmente fueron muy importantes como aquellas que rechazaron basurales, zonas de sacrificios, caletas de pescadores que reaccionaron a la pesca de arrastre, etc.

52.050 heridos por disparos de balas, perdigones, bombas lacrimógenas y balines, un número indeterminado de personas torturadas y violadas (777 querellas por tortura y 137 por abuso y violencia sexual), más de 40 muertos en distintas circunstancias, 359 personas con traumatismo ocular, varias decenas con pérdida de uno o ambos globos oculares por balines y bombas lacrimógenas, atropello a manifestantes y una larga lista de atrocidades que violan flagrantemente los $\mathrm{DDHH}$.
} 
que avalaron y validaron las medidas represivas y violentas y concurrieron con sus votos para la aprobación de leyes que criminalizaban cada vez más la protesta social y la impunidad.

Dentro de este contexto es que surge la pregunta sobre cuál es la responsabilidad ético-política en la defensa de los Derechos Humanos y la justicia social que debiésemos asumir. Considerando nuestra posición y experiencia profesional, planteamos y centralizamos la pregunta para aquellos/as que nos vinculamos al Trabajo Social Contemporáneo desde la institucionalidad en crisis, ya sea desde la academia (pública o privada), así como desde la acción gremial y territorial. De esta manera este artículo busca establecer las coerciones actuales de esta disciplina y cómo ello influye en su accionar para levantar, repensar y relegitimar el actuar de los Trabajos Sociales Otros o críticos en estos u otros escenarios de crisis del modelo capitalista neoliberal en perspectiva de co-construir significados de las dignidades y dignificaciones en perspectivas descoloniales.

\section{Sobre la Metodología}

Se inscribe y escribe en los márgenes de la vida profesional y estudiantil que muchos/as han vivenciado en los últimos años y en la contingencia que rodean esas experiencias, ya sea en sus fuentes laborales, educativas y/o cotidianas. Las "revueltas populares", "disidencias", "estallidos" y/o movimientos sociales contrahegemónicos en Latinoamérica (Chase-Dunn, Morosin y Álvarez, 2017) se han presentado de manera general y específica en distintas naciones de la región impactando directa y/o indirectamente el quehacer del Trabajo Social.

Ello, no es solo una casualidad ni una paradoja al momento de retomar el sentido y validez de los Trabajos Sociales Otros o críticos, especialmente ante la aparición de estas "resistencias" como respuestas transversales a las catástrofes humanitarias que ha ocasionado el sistema capitalista y las democracias neoliberales (Zibechi, 2020). Igualmente, la aparición desastrosa del COVID-19 en el planeta, y particularmente en Latinoamérica, hacen imprescindible el rencuentro con la sistematización, ya sea intra y/o entre comunidades, para dar cuenta y democratizar las solidaridades emergentes, así como las diversas muestras de co-laboración local en los territorios:

sino se inscribe como una potente herramienta conceptual que permiten ser combinadas con libertad, ejercitando otros modos de explorar las realidades que habitamos y queremos transformar (Gentili, 2018).

Si bien se escribe y reflexiona desde la academia son muchas las experiencias alternativas y de resistencia que se desarrollaron en Chile y Suramérica y a las cuales vinculamos en el pasado y que ahora nuevamente emergieron y proliferaron a lo largo del país. ${ }^{6}$. Como académicos hemos acompañado tanto organizaciones como estudiantes que participan de dichas iniciativas, igualmente hemos buscado, preguntado y aprendido de estas iniciativas y sus métodos diversos y su multiplicidad de metodologías en tanto utilizan "categorías horizontales y orgánicas". Estas experiencias investigativas, así como sus sistematizaciones, se han desplazado para producir conocimiento y saberes no sólo desde la escucha de las voces, sino incorporando su gramática política que surge desde la experiencia-práctica, disponiendo igualmente de múltiples instrumentos a través de los cuales se da cuenta de acciones reales y transformadoras de la

6 Ollas comunes, Resistencias feminista, Circo Social, Organizaciones comunitarias emergentes, alimentación saludable en los territorios, organización mapuche urbana etc. 
materialidad y la subjetividad histórica que acompaña a todos/as los/as que se encuentran "palpitando la realidad".

Este escrito es el resultado de aquella historia personal y académica de sus autores que han acompañado muchos de estos procesos como asesores metodológicos que se vinculan a la experiencia popular y militante de estudiantes y profesionales que han requerido el acompañamiento reflexivo-práctico para el registro de sus acciones praxiológicas, el aprendizaje, la evidencia política transformadora y la generación de conocimiento en distintos territorios y que levantan y/o participan directamente con propuestas transgresoras en distintos ámbitos.

Nuestro objetivo es que profesionales y estudiantes que se han involucrado en contextos de resistencias subalternas y que enfrentan el "orden establecido" encuentren una retroalimentación dialéctica y enriquezcan los aspectos teóricos y prácticos que "emergen confundidos" en un movimiento socio-temporal que ata la vida cotidiana con aspectos estructurales. Es en este contexto que se inscribe este documento para evidenciar que además la sistematización encuentra el desafío de incorporar las nuevas miradas descolonizadoras y líneas metodológicas significativas para impulsar procesos de transformación y dignificación.

\section{Trabajo Social y la Represión Política en la Crisis}

La crisis político-social-económica estalla en momentos en que las estructuras de poder continuaban con su estrategia de cierre a nuevas disidencias y con la represión o contención obstinada de las demandas sociales que se articulaban en la desobediencia, hastío, desafío, como o rebeldía; las exigencias ciudadanías se constituyeron en una multitudinaria fuerza movilizada que se erigió como un contra poder que disputaba la hegemonía del proceso político-social utilizando la participación colectiva y su capacidad de convocatoria para establecer una nueva agenda política, orientada a la generación de un modelo alternativo distinto al neoliberalismo existente. En ella, "convergen una multiplicidad de deseos y afectos que se unen, y lo más interesante, sin que se suprima lo diverso o lo heterogéneo de los intereses de quienes concurren a las manifestaciones". (Zarzuri, 2020, p. 2).

Sin embargo, está rabia y fastidio desatado en octubre de 2019 , no obedece a una situación coyuntural, sino que nos enfrentamos a olas o ciclos de protesta que, a diferencia de otras movilizaciones, no se ha focalizado en arremeter sobre una parte del sistema implorando reformas, sino que las protestas son contra la totalidad del sistema capitalista, o sea, se asiste a una demanda por construir una sociedad distinta, donde la vida pueda ser vivida dignamente. Se genera, entonces, un tipo de acción colectiva que es desarrollada por personas que no tienen acceso a las instituciones, o si lo tienen, estas no entregan lo que la ciudadanía busca, al contrario, se precarizan y burocratizan más las ayudas y soluciones, y peor aún, las reivindicaciones, demandas y derechos son conocidos por el sistema, pero no son aceptadas, convirtiendo esas reivindicaciones y derechos en una amenaza a sus intereses.

Es necesario entonces recordar que el Trabajo Social surge como un instrumento de intervención estatal, funcional al proyecto hegemónico del capital (Lamamoto, 1992; Netto, 1992; Montaño Barreto, 2004; Vivero, 2017). En este escenario, los/as trabajadores/as sociales han sido el cuerpo operativo y no deliberativo en la implementación del modelo neoliberal y "su desarrollo social" fallido. Estas/os profesionales se fragmentaron en diversas miradas que van desde la disciplina utópica, que cultiva la academia, hasta la profesión transformada en un "quehacer paragubernamental" sumergida, empantanada y anclada en las contradicciones estructurales que ofrecieron "los modelos de intervención focalizados" sobre la base de políticas 
sociales compartimentadas o intersectoriales que se contrapusieron a la búsqueda de la universalidad, asumiendo sin cuestionamiento las orientaciones tecno-económicas neoliberales. Los resultados de estas políticas de focalización nos indican que no tiene una incidencia positiva para las personas ni a corto ni largo plazo y han contribuido en la práctica a la consolidación de un "malestar" que se manifestó en las calles y que sumió la mirada de programas y políticas sociales y el lastre de sus prácticas "interventoras" y asistencialistas, es más, observamos con profunda preocupación que la atención gubernamental para la salida de la crisis esté en profundizar nuevas políticas económicas asistencialistas y paliativas ${ }^{7}$ que profundizan el modelo neoliberal restituyendo el clientelismo donde lo político pierde importancia y se supedita a lo técnico que vigila la sobrevivencia invisibilizando las diversas comunidades y al pueblo en general.

Si bien en la actualidad se continúa enfrentado la precariedad esencialmente desde las condiciones materiales de las/os usuarias/os de beneficios sociales, no es menos importante reconocer que también existe un concepto de precariedad que se ha internalizado en las subjetividades y el imaginario profesional que ha provocado una naturalización de la vulnerabilidad. En esa precariedad abstracta, la inseguridad y la fragilidad dejan de ser fenómenos marginales para materializarse como visión unívoca que enfrenta la definición de lo social. Esta subjetividad internalizada establece una clave entrópica en la interpretación y compresión de los actuales contextos de crisis y levantamientos populares para las políticas neoliberales vigentes, es decir, no se tiene la capacidad para mirar fuera de ese esquema referencial de precariedad.

Esta forma de regulación y enfrentamiento de la política social, la somete a un disciplinamiento a los/as profesionales, al menos, a tres dimensiones: por un lado, una forma de gobierno, traslapado también a las acciones públicas, basada en políticas y medidas destinadas a consolidar la incertidumbre e inseguridad, en todos los planos, como condición/experiencia normalizada. Un segundo elemento está dado por un modo de vigilancia, control y regulación basado en un aprehender y en la interiorización de la inseguridad e incertidumbre como principio de definición subjetiva, como principio de subjetivación. Y como un tercer elemento, un disciplinamiento objetivo/subjetivo condicionado a un orden social establecido por el "poder para enfrentar la precariedad" y que se materializa en represión y violencia sobre todo si la inseguridad e incertidumbre se vuelcan en manifestaciones populares masivas. El resultado de estos procesos es la continuidad del modelo por la fuerza y la emergencia de unas nuevas formas de materialización del poder configurado en torno a la violencia estructural que sistemáticamente padecen, cada vez más, gran parte la población.

Es que los efectos de la crisis se están distribuyendo de manera desigual entre las generaciones, siendo los jóvenes los más afectados, puesto que están sufriendo la transformación de un modelo productivo y una sociedad que han heredado, sin la protección de un sistema laboral y social que está en claro peligro de extinción (Carbonero, Caro et al., 2012, p. 13).

El Trabajo Social contemporáneo colonizado, tanto en la academia como en la práctica profesional, se ve inmerso y tensionado en un proceso cada vez más profundo de privatización de los derechos, es decir, al proceso en el cual el traspaso del poder de determinar y configurar su contenido termina recayendo en instituciones privadas y en el contexto del estado neoliberal

\footnotetext{
7 Un ejemplo claro de ello es cómo se ha enfrentado la crisis de la pandemia del Covid-19, donde las ayudas estatales han sido muy precarias, muy focalizadas y se ha traspasado a los trabajadores y familias la supervivencia. Ejemplo de ello son la utilización del seguro de cesantía, los retiros del $10 \%$ de las pensiones, la exclusión de amplios sectores de bonos y ayudas gubernamentales.
} 
subsidiario. Como consecuencia, se termina por mercantilizar la salud, la educación o recursos tan elementales como el agua. Este proceso es referido por algunos autores como una dinámica de mercantilización de la vida o como fetichización de lo social.

Los beneficios de la asistencia social hacia, por ejemplo, las infancias vulnerables o el derecho a una vivienda digna pasan a ser administrados por organismos externalizados por el estado, pero gestionados y operados por trabajadores/as sociales cuyos beneficiarios son quienes no tienen el capital para ello sobre la base de políticas públicas asistenciales, muy focalizadas y excluyentes. Esta privatización de derechos materializa la mercantilización de la asistencia perceptible en la tercerización de servicios a empresas privadas y en la proliferación de relaciones de clientelismo en torno "a grandes estructuras que captan cuantiosos recursos, recurriendo incluso a técnicas propagandísticas y de marketing» (Barrera, Malagón y Sarasola, 2013, p. 120).

Estas acciones contenidas y reguladas por el modelo neoliberal y ejercidas y ejecutadas por trabajadoras/es sociales, han contribuido, no exclusivamente, significativamente a la conflictividad política y social que se vive en Chile desde octubre del 2019. La evidencia de un "sometimiento profesional al modelo" transformó al Trabajo Social en un instrumento de control biopolítico de los cuerpos precarizados y vulnerados socialmente. Ello demuestra una debilidad crítica en el enfrentamiento ético-político a las políticas sociales neoliberales ante lo cual es esencial abrir debates y participar directamente ante la generación de nuevos espacios de acción social a partir de la eventual superación del Estado subsidiario. En otras palabras, la colonialidad se ha hecho carne en la profesión; resaltando un pensamiento crítico funcional al modelo, en la naturalización del clientalismo, en la estereotipación de la pobreza y los pobres, en la aplicación de modelos universalitas de soluciones, por nombrar algunas.

Más allá del ámbito profesional, es importante señalar que se ha ido consolidando una paradoja en el cambio en la concepción de la ayuda solidaria. Por un lado, existe una resemantización de esta práctica solidaria que otorga a la comunidad una identidad de organismo privado que colabora y se preocupa del bienestar de sus integrantes del cual se desvincula el estado. De este modo, las respuestas a las problemáticas sociales, a sus demandas, a las injusticias y la violación de derechos, ya no dependen de la "intervención" activa del estado sino de las "comunidades activas y autónomas" o grupos de ciudadanos/as con capacidad asistencial para organizarse y gestionar las urgencias que el Estado no atiende o deja de atender, dejando su lugar a las comunidades y organizaciones sociales ${ }^{8}$, en otras palabras, la resolución, atención y solución de las problemáticas sociales las asumen las personas, grupos familias, agrupaciones vecinales, asociaciones voluntarias u otras del mismo carácter para impulsar, "loterías", "bingos", "fiestas", etc. En este proceso, la paradoja se produce cuando la transferencia de estas responsabilidades y obligaciones se reformulan desde una perspectiva crítica pasando de ser concebida más allá de una "urgencia asistencial" transformándose en una respuesta política de justicia comunitaria siendo entendida y ejercida como deber ético que supera la responsabilidad del Estado.

Estas prácticas solidarias con su correlato discursivo que afectan a las acciones desarrolladas por trabajadoras/es sociales han contribuido a la generación de organizaciones territoriales compuesta de personas autónomas, capaces de elaborar sus propios proyectos comunitarios y responsabilizarse del devenir y de las consecuencias del mismo, esto es, sujetas/os

\footnotetext{
${ }^{8}$ No referidos a la sociedad, dado que la gestión de soluciones está afincada en estos grupos y organizaciones que funcionan muchas veces independientemente 0 a veces conjuntamente, pero no como un todo.
} 
emprendedoras/es de sí mismos que asumen logros y fracasos en términos individuales y colectivos, rearticulando el tejido social existente.

Toda esta incapacidad de los "servicios sociales neoliberales" que se "ofertan" a las comunidades vulnerables contribuyó, de manera significativa, a la acumulación de frustraciones, de injusticias e indignidades de los sectores precarizados y no tan precarizados y que terminaron estallando en una revuelta popular colocando al Trabajo Social en una encrucijada sustantiva. La nueva configuración social coloca otra vez en el centro la tensión que ha acompañado desde sus inicios al Trabajo Social; la tensión que contrapone la lógica de la acción social, transformadora y liberadora, a la lógica tradicional y de sometimiento a prácticas asistencialistas. Esta tensión alimentará todas las figuras paradójicas en que encuentran las/os trabajadoras/es sociales en lo cotidiano y que sistemáticamente producen quiebres profesionales y negaciones de realidades.

Este emergente reordenamiento social, político, económico y cultural donde la propia comunidad exige definiciones para posicionarse en un "espacio social otro", sumado al factor pandémico del Covid-19 han originado contextos de inestabilidad praxiológica, e inclusive epistémica, que empujan a las trabajadoras/ores sociales a definirse respecto del modelo de dominación existente.

Lo ocurrido en Chile, volvió a desnudar los locus profesionales del Trabajo Social chileno que se desvinculó profesionalmente de acciones con comunidades u organizaciones autónomas o movimientos sociales. El Trabajo Social siguió un rumbo institucionalizado transformándose en una "disciplina paragubernamental" naturalizando sus funciones y competencias como parte de la estructura de agentes sociales del estado. Las comunidades autónomas y movimientos sociales solo fueron "cosificados" desde procesos investigativos que no tuvieron la capacidad para vincularse a las luchas de estos sectores. Es más, se levantaron muchísimos seminarios y conversatorios virtuales, pero al final del sendero, las prácticas, el asistencialismo y el acomodo al modelo siguió casi sin alteraciones. Entonces, la pregunta que sigue rondando, y aún sin respuesta, es ¿Por qué?

Se puede esbozar una respuesta desde la sospecha y es que no sabemos cómo posicionarnos desde otros espacios no institucionalizados, resulta complejo a lo menos pensar la acción profesional en otros lugares más allá de las instituciones tradicionales, desde lógicas comunitarias y colaborativas, simétricas, con un actuar y accionar desde la "acciones praxiológicas y los encuentros", donde colapsan y fracasan los "modelos de intervenciones", asimétricos, universalistas y mesiánicos. Pensar políticas sociales fuera de las estrategias subsidiarias es casi imposible, lo que se agrava pues tampoco en las universidades encontramos posibilidades de caminos alternativos, en estas instituciones priman el conocimiento científico estratificado de acuerdo a nociones cortoplacistas de utilidad inmediata y competente o de transferencia para realizar ajustes a políticas y programas sociales neoliberales.

En esta misma medida, a las políticas públicas no les compete corregir estas dinámicas, sino generar dispositivos capaces de posibilitar la autorregulación de lo social. Los mecanismos de intervención se reducen a evitar situaciones de riesgo que impidan el buen funcionamiento autónomo, autorregulado, de lo social (Abad y Martín, 2015, p. 181).

Puestos es esta encrucijada es que se quiere proponer algunas ideas de cómo los trabajos sociales pudiesen vincularse, empaparse y proyectarse en estos escenarios tan inestables y riesgosos. 


\section{Nuevos Trabajos Sociales. Praxis desde los Márgenes de las Praxis}

Más allá de las fronteras de Chile, la preocupación y descontento de sectores importantes del planeta respecto del modelo de desarrollo económico se ha constituido en un factor gravitante. Este desasosiego se ha transformado en una disputa donde, por un lado, se presentan y activan movilizaciones colectivas orientadas a denunciar y visibilizar sus consecuencias e imponer al poder modificaciones sustanciales que permitieran de alguna manera avanzar en el alivio y/o soluciones parciales a los problemas planteados por la propia dinámica del capital. Por otra parte:

Los cambios que estamos viviendo no deben hacer olvidar que tanto el imperio como las elites locales tienen aún el suficiente poder como para intentar bloquear los avances y desgastar a los gobiernos que toman distancias de Washington. (Zibechi, 2006)

La historia ha demostrado que muchos de los levantamientos sociales originados en Latinoamérica fueron abortados con la reinstauración del orden político institucional a través de la represión y de la violación de los derechos humanos, pero también se han presentado experiencias exitosas, dando lugar a prefiguraciones de sociedades postcapitalistas, experiencias donde se ha podido establecer prácticas y procesos en un sentido antagonista a las prácticas dominantes, en forma de contrasentido a las mismas, ya sea porque su racionalidad cultural procede de otras culturas aún vivas, comunitarias o bien han sido resistentes a las fuerzas homogeneizadoras de la modernización capitalista. Con ello se puede afirmar que desestabilizar la racionalidad dominante, pasa por procesos en los cuales se produce una radicalización de la participación de las comunidades y una nueva concienciación de la pluralidad, paralelo a la puesta en marcha formas económicas cooperativas alternativas.

La pregunta que surge es ¿En Chile, este último escenario, se está configurando? Ante una respuesta afirmativa sería necesario retornar a aquellos lugares que hemos invisibilizado, donde se construye y co-construyen los cambios y las metamorfosis, donde realmente pueden desarrollarse unos Trabajos Sociales liberadores y transformadores. Desde esta idea, nos parece interesante lo que plantean Ganter y Zarzuri, respecto a que los Trabajos Sociales debiesen mirar en función de sus praxis sociales y la formación profesional:

(a) una visión alternativa de mundo, que implica nuevas concepciones de lo público, lo político y la democracia;

(b) una forma alternativa de vivenciar-estructurar la organización y la participación ciudadana, que implica una fuerte despartidización de la política en beneficio de otras orgánicas menos jerárquicas y más rizomáticas;

(c) la escenificación innovadora de repertorios de acción colectiva de fuerte contenido simbólico y emocional, que implican una potente interacción ritual entre el arte, el 
cuerpo, lo festivo y lo digital como herramientas al servicio de lo que aquí llamamos activismos de tipo convergentes, donde se sincronizan múltiples causas y agendas ciudadanas heterogéneas al interior de una subjetividad colectiva o singular (2020, p. 98).

En definitiva, repensar y ordenar los Trabajos Sociales, que debiesen orientarse hacia la generación de procesos de autogestión social desde una lógica multidimensional e integral, a la co-potenciación de la participación real, a las praxis sociales desde la desinstitucionalización ${ }^{9}$. Situarlos y situarnos en el centro como co-constructores colectivos de nuevas formas de sustanciar las problemáticas locales o comunitarias, implicaría volcarse sobre las comprensiones de los imaginarios de las personas para buscar desarrollar nuevas subjetividades sobre el rol que se debe desempeñar por la disciplina en este escenario, centrado fundamentalmente en entender la "realidad y sus demandas" desde la participación de las comunidades y no desde los/as expertos/as.

En este periodo de latencia de las energías del estallido social, se piensa que mantener una neutralidad disciplinaria e institucional podría tener efectos deslegitimadores significativos. Aun existe una posición hegemónica de reconocer y pensar a los/as trabajador/as sociales como mediadores en los conflictos de distinta naturaleza, pero mantener este silencio es insostenible. Esta posición hace que se mantenga la incertidumbre, ya que impide tomar partido por las personas vulneradas por el funcionamiento de la máquina social del modelo capitalista, a riesgo de parecer irresponsable y de desacreditarse, pero tampoco puede colocarse al lado de los mandatarios de la sociedad que demandan su acción, a riesgo de convertir ésta en ineficaz hacia quienes son sus públicos objetivos. "En concreto, nos encontramos con una práctica profesional crecientemente marcada por el control, la sanción y la burocracia” (Bermejo, 2016).

Esta especie de limbo profundiza el desperfilamiento, la confusión epistemológica y praxiológica, pero para salir de este espacio oscuro es necesario enfrentar un doble reto ineludible.

por un lado, una necesaria adaptación a la realidad presente; por otro, la no menos importante lucha y reivindicación a favor de los derechos sociales ameritados y de los que es necesario reconocer en un panorama de intensificación de la vulnerabilidad (García-Domingo y Sotomayor-Morales, 2017, p. 49).

Las múltiples crisis y lo insostenible que se hace el sistema, redundará en nuevas olas de levantamientos populares cada vez más cercanas temporalmente y que interpelan a los Trabajos Sociales. Ante ello se propone algunos caminos para la reflexión, actuar y reconocerse. Estas no tienen la pretensión de verdad, más bien, son posibilidades a explorar, a intentar, a activar, de esta manera se piensa contribuir en la búsqueda de las coerciones

\footnotetext{
${ }^{9}$ Esto no quiere decir que se excluya al Trabajo Social que responde a el aparataje estatal e institucional, inclusive si su lógica sigue siendo asistencialista-clientalista, pueden convivir temporalmente, aunque lo que proponemos es avanzar a otras formas no institucionalizadas, más comunales para nuestra praxis profesional.
} 
actuales de esta disciplina y cómo ello influye en su accionar para repensar el actuar de los Trabajos Sociales Otros desde una perspectiva crítica en esta coyuntura de crisis del modelo capitalista neoliberal en perspectiva de co-construir significados de las dignidades y dignificaciones en perspectivas descoloniales.

1. Desarrollo de estrategias de encuentros con comunidades situadas en la acción: Es urgente superar el estado subsidiario y sus políticas sociales neoliberales, así como sus programas y proyectos centralizados y estandarizados en el logro de objetivos. Se requiere la creación de una forma diferente de "acercamiento a las realidades territoriales" así como, a la noción del mundo, del otro/a. Se requiere una acción social diversa y desfocalizada de los territorios y sus comunidades. Es urgente, en el actual escenario, volver a los grupos y sus contextos, a sus lugares de proximidad, invocando al protagonismo grupal, a las redes sociales, para la resolución de sus problemas reales y situados bajo criterios de descentralización más allá del control técnico de las políticas sociales reguladoras.

2. Desarrollo de estrategias de superación de las subalternidades: Es fundamental recuperar las diferentes formas de articulación necesarias entre el pensamiento y la acción liberadora, entre la teoría y la práctica concientizadora que se potencia una perspectiva crítica que propicie diferentes formas de lucha y resistencia al pensamiento y acción neoliberal donde el desarrollo de la acción colectiva y militante descolonizadora es fundamental.

Los Trabajos Sociales Otros debiesen superar el espacio institucional y vincularse con las fuerzas impulsoras de una política social capaz de transformar y construir no sólo en el espacio público, sino también colaborar en el impulso de las condiciones políticas para la emergencia de una cultura basada en la multiplicidad, la diferencia, la subjetividad y lo común. Ello implica participar en el seno de las luchas, en las acciones que llevan adelantes los diversos colectivos, es estar ahí, no como personas naturales sino como trabajadoras y trabajadores sociales, pues en esos espacios se están construyendo y configurando los nuevos espacios sociales, las nuevas humanidades, pues: "Las territorializaciones y las prácticas artístico-productivas de estos sujetos problematizan la gubernamentalidad basada en la simple convergencia u oposición binaria Estado/Mercado y Público/Privado" (Roldan y Godoy, 2020, p. 112).

3. Desarrollo de tácticas de co-construcción de redes comunitarias enlazadas: Las comunidades territoriales han demostrado su energía de cambio y su potencia como sujetos/as históricas/os. La creación de la utopía del "colectivo" es una realidad en el espacio comunitario, la co-construcción de asociatividades y redes de las mismas es fundamental. Avanzar desde el colectivo con participación real y relacional. Lo vivenciado ha permitido discusiones y sistematizaciones que colaboran con las diferentes experiencias de lucha de las organizaciones. Y el papel de las/os trabajadoras/es sociales es importante, dado que pueden ser el eje de estas articulaciones y ser potenciadoras/es de la participación en los territorios.

4. Desarrollo de tácticas de acciones "Nosótricas" Relacionales: Asumiendo el sentido que propone Lenkersdorf (2008), es necesario asumir la actuación en la que todas/os las y los sujetos se hacen parte de la misma, y son actores fundantes para que ésta se lleve a cabo. En lo que respecta al sujeto, no es posible la recuperación sin una reelaboración de sus identificaciones, sin rehacer los procesos de socialización, fomentando la formación de la personalidad y experimentando la fuerza de lo valioso. Este proceso habrá de realizarse a través de estrategias no sólo de acompañamiento sino también de involucramiento que tanto trabajadoras/es sociales puedan diseñar colectivamente e 
intencionar las interacciones u co-coordinaciones entre los miembros de su comunidad como de otras comunidades o colectivos. Avanzar en la construcción de un lazo social basado en el reconocimiento, la redistribución y la reciprocidad exige no sólo cambiar las relaciones dentro del propio grupo social, sino de alguna manera cambiar, el conjunto de las relaciones sociales, lo cual pasa por tener en cuenta quizá más en cuenta la interacción social con el medio ambiente y los ecosistemas (García, Gutiérrez et al., 2016, p. 15).

Actuar desde lo colectivo o como parte de lo colectivo es donde los Trabajos Sociales Otros materializan parte de su quehacer. Las soluciones están en la multiplicidad de miradas, no están ancladas en una sola y, como trabajadoras y trabajadores sociales, lo podemos volver a ser parte consciente de nuestro actuar profesional.

5. Desarrollo de tácticas fundadas en Praxis Sociales Situadas Sustantivas: Conlleva una trasgresión a la singularidad universalista de los modelos de intervención" pues los Trabajos Sociales Otros se asumen solidarios y militantes con las luchas que ocurren dentro del contexto multicultural con marcado énfasis en lo político y los derechos de los colectivos diversos que pueden ser "intervenidos".

[...] es la necesidad de establecer su propio orden (des-orden), donde no exista una separación entre lo personal y lo político, donde fluyan ambos ejes, sin engaño, y sin contradicción [...], donde la teoría y la práctica vayan de la mano (Costa, 2004, p. 119).

Estas prácticas prefigurativas de "Otros Trabajos Sociales" se encuentran diseminadas por el mundo rural, indígena; las eclosiones de jóvenes, de los movimientos de la indignación, en las defensas de los ecosistemas, o los movimientos que se enfrentan a los gastos antisociales de los gobiernos. Procesos en los cuales se recuperan los restos de una vida comunitaria afectiva a través de la cual el poder-dominación, se transforma en poder-hacer y en la potenciación de la autonomía de los sujetos sociales, en los cuales son los propios sujetos sociales una serie de prácticas que asumen su propio proceso de reproducción social. Precisamente, las personas en proceso de exclusión o excluidas de los beneficios del sistema pudieran tomar las riendas de sus vidas y no sintieran que fuerzas externas que no dominan ni pueden llegar a dominar los marginan. Esto supone que las estrategias que se han de llevar a cabo sean sinérgicas (todos los recursos, todas las políticas, todas las acciones tienen que ir encaminadas en la misma dirección): "Un buen grado de humildad en asumir nuestra ignorancia frente a lo que constituye la realización y la vida digna de esos "otros", nos permitiría convivir, co-existir, compartir y dejar que esos sentidos de vida nos permeen" (Gómez-Hernández, 2017, p. 146)

6. Desarrollo de tácticas Autogestoras en la Acción Colectiva: En términos prácticos podemos definirla como la manifestación de un proyecto político que se revela tanto en la emergencia en el espacio público, la mayoría de las veces de la mano de movimientos sociales o colectivos más amplios-, como en la intimidad del trabajo cotidiano autónomo. Contiene una forma de entender los "impulsos de iniciativas" y procesos de "acción soberanos" de manera situada, dejando entrever lo genuino de esta aplicación, diferenciándose en cierta medida de conceptualizaciones ancladas a visiones eurocéntricas y/o coloniales, en las que se revela el carácter "moderno" de sus sentidos, 
ya sea positivista, funcional-sistémica, discursiva/postestructural o vista desde la "complejidad" (Saavedra, 2015).

Desde esta perspectiva, los Trabajos Sociales, en tiempos de revueltas y estallidos debiesen superar las tradicionales prácticas y propuestas, estableciéndose una sincronía en lo expresado por los movimientos libertarios y junto a la exigencia de nuevas formas de democracia directa, así como la sistematización de esos procesos y del desarrollo de investigaciones situadas que den insumos a estos mismos procesos.

Volver a "enlodarnos los pies" es la consigna, estando en las prioridades de las personas, colectivos, comunidades u otras instancias organizativas desde los subalternos, es allí donde se generan los vínculos identificatorios grupales frente a la identidad de clase, etnia o género diferentes a otras identificaciones. En muchos casos estas identidades se construyen sobre la definición positiva de una identidad que ha sido negada, devaluada, o simplemente infravalorada, pero que son el motor de las transformaciones y los Trabajos Sociales Otros tendrían sentido desde esos espacios identitarios pues también son nuestros espacios identitarios.

\section{Primer Intento de Síntesis}

Son los procesos histórico-políticos asociados a la distribución social de la riqueza de los países el punto de arranque de desigualdades e injusticias sociales que se configuran como violencia estructural; formas de la convivencia social que están marcadas por la polarización del acceso a la satisfacción de las necesidades humanas entre unos pocos que las satisfacen hasta el hartazgo y una mayoría excluida de sus derechos. Chile, es un ejemplo paradigmático de cómo el neoliberalismo ha extremado este desequilibrio distributivo.

La necesidad de reflexionar ante este nuevo contexto no debe limitarse únicamente a las repercusiones que las crisis están teniendo para las personas y familias, así como para los sistemas de protección, sino también, y, sobre todo, debe contemplar las prácticas profesionales y la reconceptualización de los Trabajos Sociales Otros.

La historia disciplinaria ha transitado desde lo benéfico asistencial o caritativo, en un segundo momento como una acción aséptica, en un tercer momento como una praxis militante, en un cuarto momento como tecnocrático y desarrollista orientado hacia el ajuste y la adaptación y tal vez ahora, atravesamos un quinto momento, quizás el más complejo, por la pervivencia de dos afluentes, por una parte, como gerenciación social (acorde con el neoliberalismo) y por otra parte una que emerge de la revuelta y el estallido social encaminada hacia la conciencia liberadora descolonizadora relacionada con la participación, la organización y la movilización.

El estallido social o revuelta popular ofrece una oportunidad profesional y disciplinaria para colaborar en revertir la tradicional hegemonía de un modelo de respuesta focalizada y atomizada en la dimensión individual-familiar del "beneficio" y la "asistencia". La revuelta nos hace mirar y actuar desde los territorios organizados colectivamente, desde la potenciación del trabajo en red no sólo entre entidades y servicios del ámbito social sino entre el conjunto de agentes que operan en el seno de una comunidad. Obliga al desafío ético-político que supere los modelos de intervención basados en los lógicas subalternidad (interventores/intervenidos) con el desarrollo de praxis que planteen una acción en un marco más amplio, que trascienda los despachos, y que implique la participación activa de la ciudadanía, que recupere y potencie la creciente sensibilización de la población y de los profesionales en relación a las necesidades comunes, siempre desde sus espacios, sean estos en sus comunidades o en las protestas que ellos levantan. 
Es colocar en el centro a las personas, colectivos, comunidades, más allá del rol de protagonistas sino como autores y actrices creadores de procesos, desplazando a la/el profesional constituido como experto/a prescriptor/a de diagnósticos y soluciones a la tarea periférica de facilitador de procesos colectivos y comunitarios, revitalizando la práctica del estar/hacer/colaborar que implica trabajar los aspectos no sólo técnico sino también los emocionales que afectan a las personas colectivas como humanidades presentes.

Los nuevos escenarios que se han abierto aún son difusos y, en cierto modo, beligerantes, el descontento y los contextos tensionantes, que en muchos casos terminan en conflictos directos entre la ciudadanía y "los servicios sociales" como en la atención social de urgencia en los municipios para asignación de "bonos o beneficios" o las acciones profesionales enmarcadas en las políticas públicas. El peligro se constituye si estos "servicios sociales" comienza a ser visualizados como aparatos represivos y de contención del Estado a la demanda social, lo que en un momento de la historia disciplinaria fue reconocido como "muro de contención", lo que puede ocasionar un ciclo de violencia reactiva como los que se han presentado el personal de la salud en Consultorios o el personal de trato directo de organismos colaboradores de SENAME, que se han constituidos en un conjunto de expresiones agudas de respuesta social rupturista hacia las condiciones sistémicas que maltratan y oprimen, que generan pobreza, sufrimiento y enfermedad, que destruyen la condición ciudadana. La violencia reactiva es compleja y multiforme, va desde expresiones de segmentos organizados de la sociedad que luchan con propuestas de transformación y con estrategias y métodos propios de la acción política consciente, hasta manifestaciones anómicas de grupos inorgánicos y espontáneos.

La forma de evitar estos posibles escenarios implica estar sumergidos en las múltiples realidades de las diversas comunidades que componen los territorios y sus realidades encarnadas: desde las vivencias y luchas de los migrantes, indígenas; clases medias empobrecidas, jóvenes antisistemas, por nombrar algunas, que resguarden sus independencias y autonomías para no colocarlas al servicio de intereses corporativos o las prioridades inmediatistas de los gobiernos de turno.

En otras palabras, los Trabajos Sociales Otros deben estar en el vientre del tejido social territorial, con un sentido de reciprocidad y efectivo interés de encuentro y colaboración con la realidad referida. Recuperar las significaciones comunes, multiplicar las redes. Todo conlleva una determinada opción que, hasta el momento, también denominamos crítica. Una opción decantada hacia las esferas al margen del poder y acompañada siempre por un cuestionamiento de cualquier tipo de cánones o patrones de "normalidad". 


\section{Referencias}

Abad, B. y Martín, I. (2015). El Trabajo Social ante la crisis. Nuevos retos para el ejercicio profesional de los y las Trabajadoras Sociales. Cuadernos de Trabajo Social, 28 (2), $175-185$.

Alguacil Gómez, J. (2012). La quiebra del incompleto sistema de Servicios Sociales en España. Cuadernos de trabajo social, 25, 63-74.

Barrera, E.; Malagón, J.; y Sarasola, J. (2013). La deconstrucción del Estado de bienestar: cambios en el ejercicio profesional de los trabajadores sociales y aumento del voluntariado social. Cuadernos de Trabajo Social, 26 (1), 115-126.

Bermejo, C. (2016). El Trabajo Social como Instrumento Institucional de Control Social (Trabajo Final de Grado). Grado en Trabajo Social, Universidad de Valladolid. URL: http://uvadoc.uva.es/handle/10324/19417

Carbonero, M.; Caro, G.; Mestre, J.; Oliver, M.; Socias, C. (2012) Reconceptualizando los Servicios Sociales. Recuperar el Trabajo Social Comunitario como respuesta al nuevo contexto generado por la crisis. Documentos de trabajo social: Revista de trabajo y acción social, 51, 9-27.

Cortés, A. (23 de Enero de 2020). El octubre chileno: el neoliberalismo ¿nació y morirá en Chile? Recuperado el 27 de julio de 2021, de https://www.opendemocracy.net.

Fabrega, J. (2 de Noviembre de 2019). Aquí yace el neoliberalismo, que nació y murió en Chile. Recuperado el 27 de julio de 2021, de www.ciperchile.cl.

Ganter, R. y Zarzuri, R. (2020). Rapsodia para una Revuelta Social: retazos narrativos y expresiones generacionales del 18-O en el Chile actual. UNIVERSUM, 35 (1), 74 -103.

García-Domingo, M. y Sotomayor-Morales, E. (2017). El rol del profesional del Trabajo Social en una coyuntura de crisis: oportunidades de la adaptación a un contexto cambiante. Trabajo Social Global -Global Social Work. Revista de Investigaciones en Intervención social, $7(12)$, 47-68.

García, E., Gutiérrez, M., Maldonado, M. (2016). Movimientos sociales y Trabajo Social, enredos necesarios. En Carbonero, D.; Raya, E.; Caparros, N.; y Gimeno, C. (Coords) Respuestas transdisciplinares en una sociedad global. Aportaciones desde el Trabajo Social. (pp. 1-16) Logroño: Universidad de La Rioja. Disponible en: https://publicaciones.unirioja.es/catalogo/online/CIFETS_2016/Monografia/pdf/TC114.p df

Gómez-Hernández, E. (2017). Implicaciones para un Trabajo Social intercultural crítico y decolonial latinoamericano y caribeño. En Hermida, M. y Meschini, P. (comp.) Trabajo social y descolonialidad. Epistemologías insurgentes para la intervención en lo social. (pp. 121-154) Argentina: Editorial Universidad Nacional de Mar del Plata.

Meschini, P. y Dahulp, M. (2017). La sistematización de la intervención en lo social. En Hermida, M. y Meschini, P. (comp.) Trabajo social y descolonialidad. Epistemologías insurgentes para la intervención en lo social. Argentina: Editorial Universidad Nacional de Mar del Plata. Faltan las páginas

Monckeberg, M. O. (2019). La raíz del estallido y el fracaso del modelo neoliberal. Recuperado el 27 de julio de 2021, de https://palabrapublica.uchile.cl/2019/12/11/la-raiz-delestallido-y-el-fracaso-del-modelo-neoliberal/.

Reguillo, R. (2017). Paisajes insurrectos. Jóvenes, redes y revueltas en el otoño civilizatorio. No indica país de edición: NED ediciones.

Roldán, D. y Godoy, S. (2020). Conflictos territoriales y culturales en la renovación del frente costero, Rosario (Argentina). EURE, 46, (138), 95-116.

Saavedra, J. (2015). Cuatro argumentos sobre el concepto de intervención social. Cinta de Moebio, 53, 135-146,

Vivero, L. (2017). Influencia del neoliberalismo en el trabajo social chileno: discursos de profesionales y usuarios. Revista colombiana de ciencias sociales, 8 (1), 125-148. 
Zarzuri, R. y Henríquez, K. (2020). Primera línea: accionar desde el cuerpo, encuentros, persistencias y contra violencias en el espacio público. Santiago de Chile: LOM Ediciones.

Zibechi, R. (2006). Movimientos sociales: nuevos escenarios y desafíos inéditos. Buenos Aires: CLACSO. 